\title{
Histological evaluation of the effect of low-level laser on distraction osteogenesis in rabbit mandibles
}

\author{
Paulo-Eduardo Kreisner ${ }^{1}$, Diego-Segatto Blaya ${ }^{1}$, Lêonilson Gaião ${ }^{2}$, Marconi-Eduardo-Sousa Maciel-Santos ${ }^{3}$, \\ Adriana Etges ${ }^{4}$, Manoel Santana-Filho ${ }^{5}$, Marília-Gerhardt de Oliveira ${ }^{5}$
}

\footnotetext{
${ }^{1}$ PhD student, School of Dentistry, Pontifícia Universidade Católica do Rio Grande do Sul (PUCRS), Porto Alegre, RS, Brazil

${ }^{2} \mathrm{PhD}$. School of Dentistry, Imperatriz, MA, Brazil

${ }^{3} \mathrm{PhD}$ student, School of Dentistry, Universidade de Pernambuco, Camaragibe, PE, Brazil

${ }^{4}$ PhD. Full Professor, School of Dentistry, Universidade Federal de Pelotas (UFPel), Pelotas, RS, Brazil

${ }^{5}$ PhD. Full Professor, School of Dentistry, PUCRS, Porto Alegre, RS, Brazil
}

Correspondence:

Av. Cel. Lucas de Oliveira

841/203, Petrópolis

CEP: 90460-001 - Porto Alegre, RS, Brazil

mogerhardt@yahoo.com.br

Received: 01/07/2009

Accepted: 28/11/2009
Kreisner PE, Blaya DS, Gaião L, Maciel-Santos MES, Etges A, SantanaFilho M, Oliveira MG. Histological evaluation of the effect of low-level laser on distraction osteogenesis in rabbit mandibles. Med Oral Patol Oral Cir Bucal. 2010 Jul 1;15 (4):e616-8.

http://www.medicinaoral.com/medoralfree01/v15i4/medoralv15i4p616.pdf

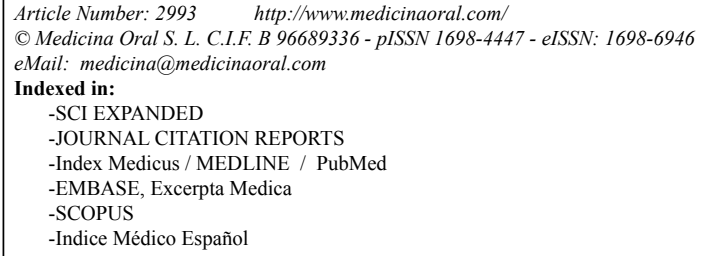

\begin{abstract}
Objectives: This study evaluated the action of low level laser therapy (LLLT) on the percentage of newly formed bone in rabbit mandibles that underwent distraction osteogenesis (DO).

Study design: Ten rabbits underwent bone lengthening according to the following protocol: Latency -3 days; Activation -7 days $0.7 \mathrm{~mm} / \mathrm{d}$; and Consolidation - 10 days. The control group was composed of 4 rabbits. The experimental group, composed of 6 rabbits, received infrared GaAlAs LLLT $(\lambda=830 \mathrm{~nm}, \mathrm{P}=40 \mathrm{~mW})$ according to the following protocol: point dose of $10 \mathrm{~J} / \mathrm{cm} 2$ applied directly on the bone site that underwent $\mathrm{DO}$ during bone consolidation at 48-hour intervals.

Results: The percentage of newly formed bone was greater in the LLLT group (57.89\%) than in the control group $(46.75 \%)(\mathrm{p}=0.006)$.

Conclusion: The results suggest that LLLT had a positive effect on the percentage of newly formed bone. Betterquality bone sites may allow early removal of the osteogenic distractors, thus shortening total treatment time.
\end{abstract}

Key words: Distraction osteogenesis, lasers, physical process, basic research. 


\section{Introduction}

Distraction osteogenesis (DO) has been shown to be an alternative treatment for facial bone reconstruction. A distraction devices is used to induce bone growth in the site of deformity (1).

Long-term stability of DO has not been well documented, and some studies have found cases of instability and recurrence (2-5). Therefore, some authors have attempted to accelerate bone maturation and to improve the physical properties of lengthened bone (6-8).

Bone regeneration creates a response involving blood vessels, cells, and extracellular matrix. Vascular supply, protein synthesis, and mineralization are all fundamental processes to guarantee tissue regeneration after trauma (9).

The use of low level laser therapy (LLLT) seems to have a positive effect on the repair of soft tissues and bone (10). DO involves metabolic events that can be modulated by using LLLT, which may reduce total treatment time and ensure, therefore, greater patient comfort (11).

\section{Material and Methods}

Experimental procedures in this study were approved by the Science and Ethics Committee of the School of Dentistry and the Ethics in Research Committee of the Pontifícia Universidade Católica do Rio Grande do Sul. Ten adult male New Zealand rabbits (Oryctolagus cuniculus) were admitted to the Animal Laboratory of the State Foundation of Health Research and Production (Fundação Estadual de Produção e Pesquisa em Saúde - FEPPS) and underwent DO of the right side of the mandible.

The animals were anesthetized with $0.1 \mathrm{mg} / \mathrm{kg} \%$ xylazine hydrochloride (Anasedan $\AA$, Agribands do Brasil, Paulínia, SP, Brazil) and $3 \mathrm{mg} / \mathrm{kg}$ zolazepam and tiletamine (Zoletil®), Virbac do Brasil Ltda., São Paulo, SP, Brazil). The right submandibular area was shaved and cleaned with $4 \%$ chlorhexidine. Sterile surgical drapes were used to isolate the operating field. Enrofloxacin $(50 \mathrm{mg})$ was administered as antibiotic prophylaxis one hour before the procedure and in the next three days. After infiltration of $0.9 \mathrm{ml}$ lidocaine and $2 \%$ epinephrine, a $3 \mathrm{~cm}$ incision was made on the skin along the lower edge of the right side of the mandible. The mandible was exposed by carefully elevating the subperiosteal plane. Burs and osteotomes were used to produce a corticotomy. The inferior alveolar nerve was preserved. The distractor (PROMM $\AA$, Porto Alegre, Brazil) was fixed to the mandible with four $1.5 \times 5 \mathrm{~mm}$ screws perpendicular to the corticotomy. The wound was irrigated with saline solution and closed in layers.

The DO was applied using a 3-day latency period, a single $0.7 \mathrm{~mm}$ daily activation of the distractor for 7 days and a 10-day consolidation period.

The animals were randomly divided into 2 groups. The control group comprised 4 rabbits, and the experimental group, 6 rabbits that received doses of $10 \mathrm{~J} / \mathrm{cm} 2$ per point at each 48 hours during the consolidation period, which totaled $50 \mathrm{~J} / \mathrm{cm} 2$. Gallium-aluminum arsenide (GaAlAs) laser was used at $830 \mathrm{~nm}$ and $40 \mathrm{~mW}$. At the end of consolidation, the animals were killed in a carbon dioxide chamber according to the recommendation of the Brazilian Committee for Animal Experiments.

The specimens were decalcified with 5\% citric acid and routinely prepared to be embedded in paraffin and stained with HE (hematoxylin and eosin). Lateromedial 4- $\mu \mathrm{m}$-thick sections were obtained, and 3 sections of each animal were selected. To measure the areas of new bone formation, each slide was subdivided into experimental units (EU) under light microscopy and 100x magnification. Images were subsequently captured with a digital camera coupled to the microscope. Images of EU were organized in files to ensure that examiners, who were previously calibrated, were blinded to study groups.

The free software ImageTool ${ }^{\circledR}$ for Windows 3.0 (University of Texas Health Science Center, San Antonio, USA) was used to measure areas of newly formed bone (NFB) in square pixels. After the measurement of the area of newly formed bone (AN) and the total EU area (AT), the percentages of newly formed bone were calculated as AN/AT*100. A t test was used for the statistical comparison of group results.

\section{Results}

The percentage of bone neoformation was used for histological evaluation. Table 1 shows the mean values of NFB by animal. These means were calculated according to the measurements of experimental units on each slide.

A t parametric test for independent samples was used to analyze measures, and results showed differences in NFB between the control and experimental groups $(\mathrm{p}<0.05)$.

Table 1. Distribution of mean newly formed bone (NFB) values according to animal.

\begin{tabular}{|c|c|c|c|}
\hline Groups & Animal & $\%$ NFB & $\%$ mean NFB \\
\hline \multirow[t]{4}{*}{ Control } & 1 & 38.07 & \multirow[t]{4}{*}{46.75} \\
\hline & 2 & 61.34 & \\
\hline & 3 & 47.01 & \\
\hline & 4 & 40.59 & \\
\hline \multirow[t]{6}{*}{ Experimental } & 1 & 53.78 & \multirow[t]{6}{*}{$57.89 *$} \\
\hline & 2 & 44.41 & \\
\hline & 3 & 63.71 & \\
\hline & 4 & 48.53 & \\
\hline & 5 & 68.27 & \\
\hline & 6 & 68.65 & \\
\hline
\end{tabular}

$* p=0.006$ 


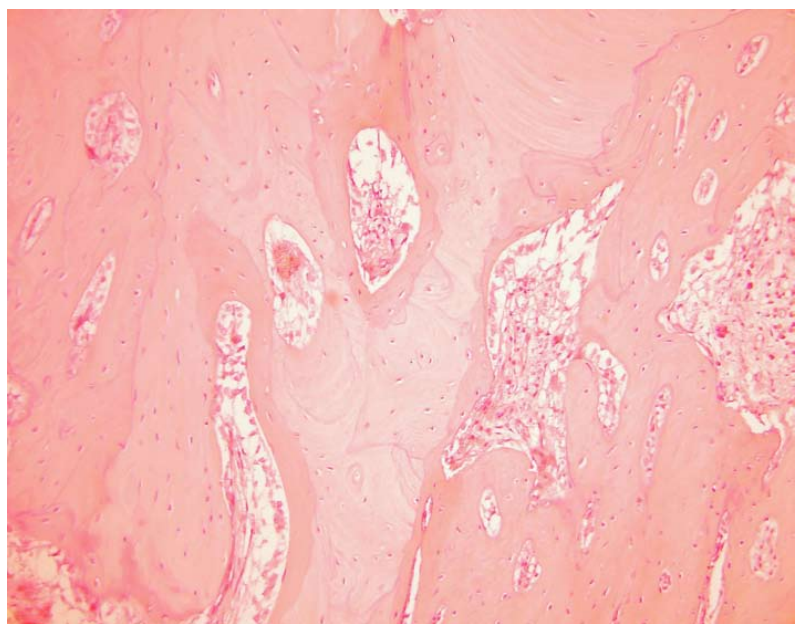

Fig. 1. Light microscopy of experimental units of rabbits that received low level laser therapy (experimental group).

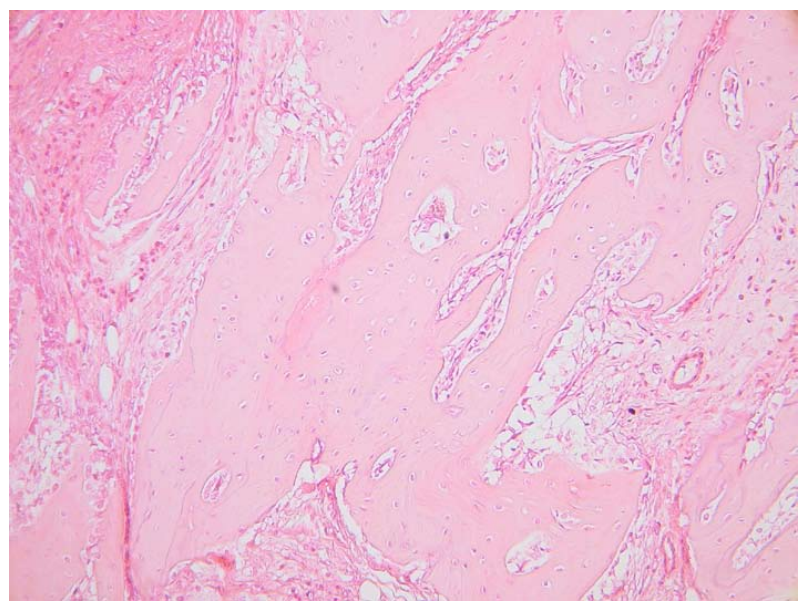

Fig. 2. Light microscopy of experimental units of rabbits that did not receive low level laser therapy (control group).

The percentage of NFB was greater in the LLLT group $(57.89 \%)$ than in the control group $(46.75 \%)(\mathrm{p}=0.006)$ (Table 1).

A statistically significant difference was found when variables were compared between groups taking into consideration non-homogeneity (Table 1), which suggests that the effect of LLLT was positive in the experimental group (Fig. 1 and 2).

\section{Discussion}

The percentage of NFB is the standard criterion to evaluate bone tissue or substitutes, and was used by Cerqueira et al. (11), Saito and Shimizu (12), and Miloro et al. (13) to evaluate DO.

The adoption of a quantitative measure, such as the percentage of NFB, reduces examiner interference found in qualitative analyses, in which the examiner describes specific items on the slides, or in semi-quantitative analysis, in which scores are assigned by the examiner to a group of items that are characteristic of a certain process. As this description or score assignment is subjectively made by the examiner, there is a greater possibility of interference on the results.

The use of an already consolidated and widely used test (HE) makes it possible to compare results, to generate innovative protocols for the use of LLLT in DO, and to reduce risks and complications inherent to this technique.

The methods used in this study and the results obtained showed that LLLT had a positive effect on the percentage of NFB in the mandible of rabbits that underwent DO.

\section{References}

1. Pereira MA, Luiz de Freitas PH, da Rosa TF, Xavier CB. Understanding distraction osteogenesis on the maxillofacial complex: a literature review. J Oral Maxillofac Surg. 2007;65:2518-23.

2. McCarthy JG, Schreiber J, Karp N, Thorne CH, Grayson BH. Lengthening the human mandible by gradual distraction. Plast Reconstr Surg. 1992;89:1-8.

3. Douglas LR, Douglass JB, Smith PJ. Intraoral mandibular distraction osteogenesis in a patient with severe micrognathia secondary to TMJ ankylosis using a tooth and bone-anchored device (PIT device): a case report. J Oral Maxillofac Surg. 2000;58:1429-33.

4. Marquez IM, Fish LC, Stella JP. Two-year follow-up of distraction osteogenesis: its effect on mandibular ramus height in hemifacial microsomia. Am J Orthod Dentofacial Orthop. 2000;117:130-9.

5. Mofid MM, Manson PN, Robertson BC, Tufaro AP, Elias JJ, Vander Kolk CA. Craniofacial distraction osteogenesis: a review of 3278 cases. Plast Reconstr Surg. 2001;108:1103-14

6. Farhadieh RD, Gianoutsos MP, Dickinson R, Walsh WR. Effect of distraction rate on biomechanical, mineralization, and histologic properties of an ovine mandible model. Plast Reconstr Surg. 2000;105:889-95.

7. Hagiwara T, Bell WH. Effect of electrical stimulation on mandibular distraction osteogenesis. J Craniomaxillofac Surg. 2000;28:12-9. 8. Shimazaki A, Inui K, Azuma Y, Nishimura N, Yamano Y. Low-intensity pulsed ultrasound accelerates bone maturation in distraction osteogenesis in rabbits. J Bone Joint Surg Br. 2000;82:1077-82.

9. Fernández-Tresguerres-Hernández-Gil I, Alobera-Gracia MA, del-Canto-Pingarrón M, Blanco-Jerez L. Physiological bases of bone regeneration I. Histology and physiology of bone tissue. Med Oral Patol Oral Cir Bucal. 2006;11:E47-51.

10. Weber JB, Pinheiro AL, de Oliveira MG, Oliveira FA, Ramalho LM. Laser therapy improves healing of bone defects submitted to autologous bone graft. Photomed Laser Surg. 2006;24:38-44.

11. Cerqueira A, Silveira RL, Oliveira MG, Sant'ana Filho M, Heitz C. Bone tissue microscopic findings related to the use of diode laser $(830 \mathrm{~nm})$ in ovine mandible submitted to distraction osteogenesis. Acta Cir Bras. 2007;22:92-7.

12. Saito S, Shimizu N. Stimulatory effects of low-power laser irradiation on bone regeneration in midpalatal suture during expansion in the rat. Am J Orthod Dentofacial Orthop. 1997;111:525-32.

13. Miloro M, Miller JJ, Stoner JA. Low-level laser effect on mandibular distraction osteogenesis. J Oral Maxillofac Surg. 2007;65:168-76.

\section{Acknowledgments}

This study was supported by Conselho Nacional de Desenvolvimento Cientifico e Tecnológico (CNPq), Brazil. 